each taking a kilowatt are used for this purpose. Views are shown of the flood-lighting employed at Croydon air-port.

\section{American Amaryllis Society}

THE first year book (1934) of this Society has recently been published under the editorship of Dr. Hamilton P. Traub (Orlando, Florida ; 2 dollars). Plants belonging to the genera Amaryllis, Hippeastrum, Crinum, Zephyranthes, Alstromeria and others are the special objects of the Society, though its interest can reasonably be expected to include such well-known plants as snowdrops, daffodils and snowflake (Leucojum). A useful classification for show purposes has been prepared, and the Fischer colour chart has been adopted as the standard of colour nomenclature. Botanical descriptions of the Amarylideæ according to Baker are given, and many pages are devoted to the breeding of the various species. Other sections deal with propagation and culture, whilst insect pests and diseases receive brief mention. Storage, forcing and marketing are also discussed. One of the most noticeable features is the brevity of each contribution, for nearly seventy articles are included in the 102 pages of the volume. The memory of Henry Nehrling, a noted raiser of Amaryllis plants, is honoured by dedication of the first year book.

\section{The Observatories Year Book 1932}

ThIs important publication of the British Meteorological Office (Air Ministry) contains a very large mass of meteorological and geophysical information, obtained at the five observatories of Lerwick, Aberdeen, Eskdalemuir, Valencia and Kew, together with upper-air observations made by sounding balloons (London: H,M. Stationery Office.) Its appearance has been slightly delayed owing to a change in its mode of production: hitherto it has been printed, but in the present issue most of the extensive tabular matter, and part of the text, is reproduced direct from typescript by the Replika process of Messrs. Percy Lund, Humphries and Co., Ltd. There is a certain loss in legibility and appearance, but this disadvantage is on the whole outweighed by the reduction in cost thus achieved; the reduction is passed on to the purchaser, since the "Year Book" now costs two guineas (postage extra) instead of three as for the preceding volumes. The volume provides a very important record of the meteorological and magnetic conditions over the British Isles during 1932.

\section{American Expedition to Tibet}

AN expedition of the Academy of Natural Sciences of Philadelphia has recently left Yachow in Szechwan Province, China, for a year's survey of the zoology of eastern Tibet. The party is under the leadership of Brooke Dolan of Philadelphia who, with some of his staff, has had previous experience in the western China area. Its main object is to obtain information and material for habitat groups of typical Tibetan animals, such as the wild yak, wild horse, ammon sheep, snow leopard, Tibetan gazelle and bear; and as an aid to this end motion pictures will be taken of the wild game, which is said to be abundant on the high steppes of Kuku-nor and Tsaidam. Mr. Dolan's party is working in co-operation with the Metropolitan Museum of the Academia Sinica in Nanking. It is gratifying to find that expeditions in out of the way parts of the world are concentrating more upon observation of animal distribution and habits than upon the unrestrained collecting which was often divorced from any sort of ecological observation.

\section{Age of a Stone Curlew}

A short note (Proc. Roy. Zool. Soc. N.S. Wales, 1933-34) records the presence in a suburb of Sydney of a fine specimen of stone curlew, which has attained a great age for such a bird. He was brought to Sydney in his third year, and by the end of 1934 he will have passed his twenty-ninth birthday; during all the time he has been allowed absolute freedom in the garden. More information regarding this interesting bird would have been welcome. On what has it been fed during these years, for the food of waders is not always easy to obtain ? Also, has it ever shown any movements suggestive of a desire to migrate at the proper season?

\section{International Inquiry into Television}

THE Rome correspondent of The Times states that the executive committee of the Institute of Educational Cinematography has decided to set up an international committee to study the problems raised by television. The committee, which will be composed of representatives of national organisations in Europe and America interested in television, will inquire into the condition of television in the various countries and the questions raised by its practical utilisation; the relations between television and cinematography; and the use of television for cultural and educational purposes.

\section{Scientific Research in Japan}

THE report of the National Research Council of Japan for the year ending March 1933 shows that, during the year, meetings of the following divisions of the Council were held: administration, astronomy, geophysics, chemistry, physics, geology and geography, agriculture, medical sciences, engineering and mathematics. Each division has sectional committees which deal with branches of the work, as for example, dyestuffs, industrial research and radio research; and delegates attended the meetings of the International Unions of Astronomy at Cambridge, Mass., and of Mathematics at Zurich. The urgent necessity of encouraging and supporting scientific and industrial research has led to the formation of a "Foundation for the Promotion of Scientific and Industrial Research of Japan" which was incorporated in December 1932 with an annual Government grant of 700,000 yen for current expenses. 